\title{
Validity experiment of dipping method in the manufacture of metal- ceramic substructure
}

\author{
Wan-Sun Lee', Su-Yeon $\mathrm{Im}^{2}$, Wook-Tae Kim* \\ 'Department of Health Science, Graduate school, Korea University, Seoul, Republic of Korea \\ ${ }^{2}$ Department and Research Institute of Dental Bioengineering, Yonsei University, Seoul, Republic of Korea \\ ${ }^{3}$ Department of Dental Technology \& Science, Shin-Han University, Uijeongbu, Republic of Korea
}

Purpose: The main purpose of this study is to suggest application plan of dipping method by comparing \& analysing the difference between addition method and dipping method in the manufacture of metal-ceramic substructure of maxillary central incisor (\#1), followed by assessing the work efficiency. Materials and Methods: Master die and hard plaster-copied one were produced and then a total of 20 copies, 10 copies for each through addition method and dipping method, were manufactured and experimented. Copings were fixed on the abutment model and invested in epoxy mounting cup. Samples were cut in labial and lingual direction, using cutter and then rubbed on sandpaper, whose 4 points were measured by using digital microscope. Results: The comparison of mean values by using t-test, parametric statistical method, shows overall significant difference $(P<0.05)$. Conclusion: The result of this study can be suggested as an application plan, since there is no significant difference between addition method and dipping method in the manufacture of metal-ceramic substructure. (J Dent Rehabil Appl Sci 2015;31(1):26-32)

Key words: dipping method; metal-ceramic substructure; validity; addition method

\section{서론}

인공적 수복물은 인체 조직, 기관의 일부 또는 전부가 상실되었을 때 인공적으로 회복시켜 주는 것을 의미하며 의안, 의수족, 의치 등이 있다.

치과보철학은 인공적 수복물을 자연치의 결손부에 회 복하여 줌으로써 환자의 저작, 발음, 기능, 심미성 등을 회복 시켜주는 치의학의 한 분야이다.

치과보철물은 발치 된 치아나 그 주위조직의 저작, 발 음, 심미성 및 편안함을 회복시켜주는 인공적 장치물이다.

제작 과정은 인상체를 이용하여 작업모형을 제작하고 납형 조각 후 매몰하여 lost wax technique으로 주형을 만 들어 주조를 통하여 하부구조의 주조체(metal frame)를

*Correspondence to: Wook-Tae Kim

Assistant Professor, Department of Dental Technology \& Science, Shin-Han University, 95 hoam-ro, Uijeongbu, 480-701, Republic of Korea

Tel: +82-31-870-3428, Fax: +82-31-870-3429, E-mail: wrdeul@hanmail.net

Received: November 6, 2014/Last Revision: February 6, 2015/Accepted: January 8 2015
제작 및 연마 등 연속적으로 이루어진다. ${ }^{1}$

이 과정 중 납형 제작은 1차적인 initial wax up으로 행 해지는데 지대치의 표면에 wax를 얇게 입혀주는 방법으 로 반복첨가법과 침적법이 있다.

반복첨가법은 알콜램프를 이용하여 조각도에 열을 가 해 지대치에 wax를 도포하여 납형을 제작하는 방법으로 분리 시 어려운 점과 겹치는 선(flow line), 기포(void) 등 의 발생 및 첨가할 때 마다 불규칙적으로 응력이 발생하 는 단점이 있지만 가장 많이 사용되고 있는 방법이다.

침적법은 dipping porter의 일정한 온도로 wax를 녹여 지대치를 담갔다 들어올리는 방법으로써 dipping 시 기 술의 미흡함으로 전치부 incisal 부위에 천공 현상과 균일 한 두께로 도포되지 못하고 얇게 제작되어 한 겹 더 도포 
하는 경우와 지대치와 밀착도가 떨어진다는 문제점으로 기피하는 경향이 있으나, 실제로는 납형이 갖추어야 할 조건인 작업의 효율성, 지대치와의 긴밀한 적합도, 일률 적 두께를 갖고 주름이나 결손이 없는 완벽한 내면 형성 등의 장점을 지니고 있다. ${ }^{2}$

본 연구는 위의 두 방법의 객관적 비교를 위해 금속 도재 하부구조물을 반복첨가법과 침적법으로 제작한 후 지대치에 접합한 후 에폭시로 매몰하여 절단기로 순,설 방향으로 절단하여 절단면을 연마지(sand paper)로 연 마하여 네 지점을 측정하여, 차이점을 비교 분석하여 작 업의 효율성의 차이를 평가하여 침적법의 활용 방안을 제시하고자 하였다.

\section{연구 재료 및 방법}

\section{1. 주 모형 (master die) 과 경석고 복제모형 (hard plaster-copied die)의 제작}

시편을 제작하기 위한 1개의 주 모형(master die, 상악 중절치)은 $\mathrm{CAD} / \mathrm{CAM}$ 을 사용하여 스테인레스 스틸로 제작되었다. 경석고 모형(hard plaster-copied die)을 위 한 20개의 실리콘 몰드는 실리콘(Deguform; Degudent $\mathrm{GmbH}$, Hanau-Wolfgang, Germany)이 경화한 후에 주 모형을 제거함으로써 완성되었다. Type IV 경석고(GC Fujirock EP, GC Corp, Leuven, Belgium) 모형은 사용 설명서에 따라 혼합되어 실리콘 몰드에 부어졌다. 그리 고 기포와 같은 명백한 결함을 보인 경석고 모형이나 주 입과정 중 불완전 요소가 발생한 경석고 모형은 다시 제 작하였다. 최종적으로 20 개의 결함 없는 경석고 모형이 제작되었다.

\section{2. 반복첨가법과 침적법을 이용한 코핑의 제작}

코핑의 제작은 조각도를 이용하여 치축면과 margin부 위 및 기타 부분을 첨가하여 wax를 도포하는 반복첨가 법과 치대치를 melting wax에 침적시켜 coping을 형성 하는 침적법으로 제작하였다(Fig. 1, 2). Coping은 전용 의 CB-30매몰재(Ticonium, Albany, NY, USA)를 이용하 여 제조사가 제시한 방법으로 매몰하고 verabond $2 \mathrm{v}$ 를 사용하여 제조사의 지시에 따라 소환 주조하였다(Table $1)$.

\section{3. 코핑의 매몰}

경석고 모형과 금속 코핑의 간격을 측정하기 위한 첫 번째 과정으로 내면 조정을 하지 않은 금속 코핑 을 경석고 모형에 접합 시키고 에폭시 마운트(Epoxy mount Resin + Epoxy mount Hardener, Allied, Rancho Dominguez, CA, USA)를 $10: 3.5$ (Resin : Hardener)의 비율로 혼합하여 시편이 위치한 마운팅 컵에 주입하였 다(Fig. 3).

Table 1. Technical data of alloys

\begin{tabular}{cc}
\hline Alloy & Verabond 2v \\
\hline Type & 4 \\
Composition $(\%)$ & $\mathrm{Ni}(71.85), \mathrm{Cr}(12.6), \mathrm{Mo}(9)$, \\
$\mathrm{Nb}(4.0), \mathrm{Al}(2.5), \mathrm{Si}(0.5)$ \\
Tensile strength, psi (Mpa) & $148000(1021)$ \\
Yield strength, psi $(\mathrm{MPa})$ & $108000(745)$ \\
Elastic modulus, $\%$ & 18 \\
CTE $\left(\times 10-6 /{ }^{\circ} \mathrm{C}\right)$ & $14.1\left(25-500^{\circ} \mathrm{C}\right)$ \\
\hline
\end{tabular}
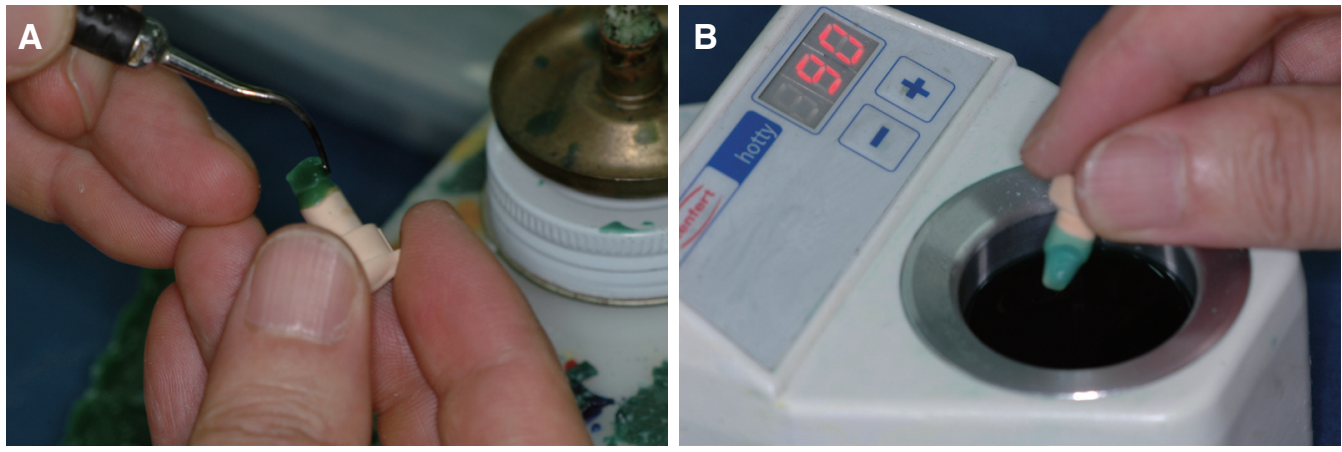

Fig. 1. View of addition method (A) and dipping method (B). 

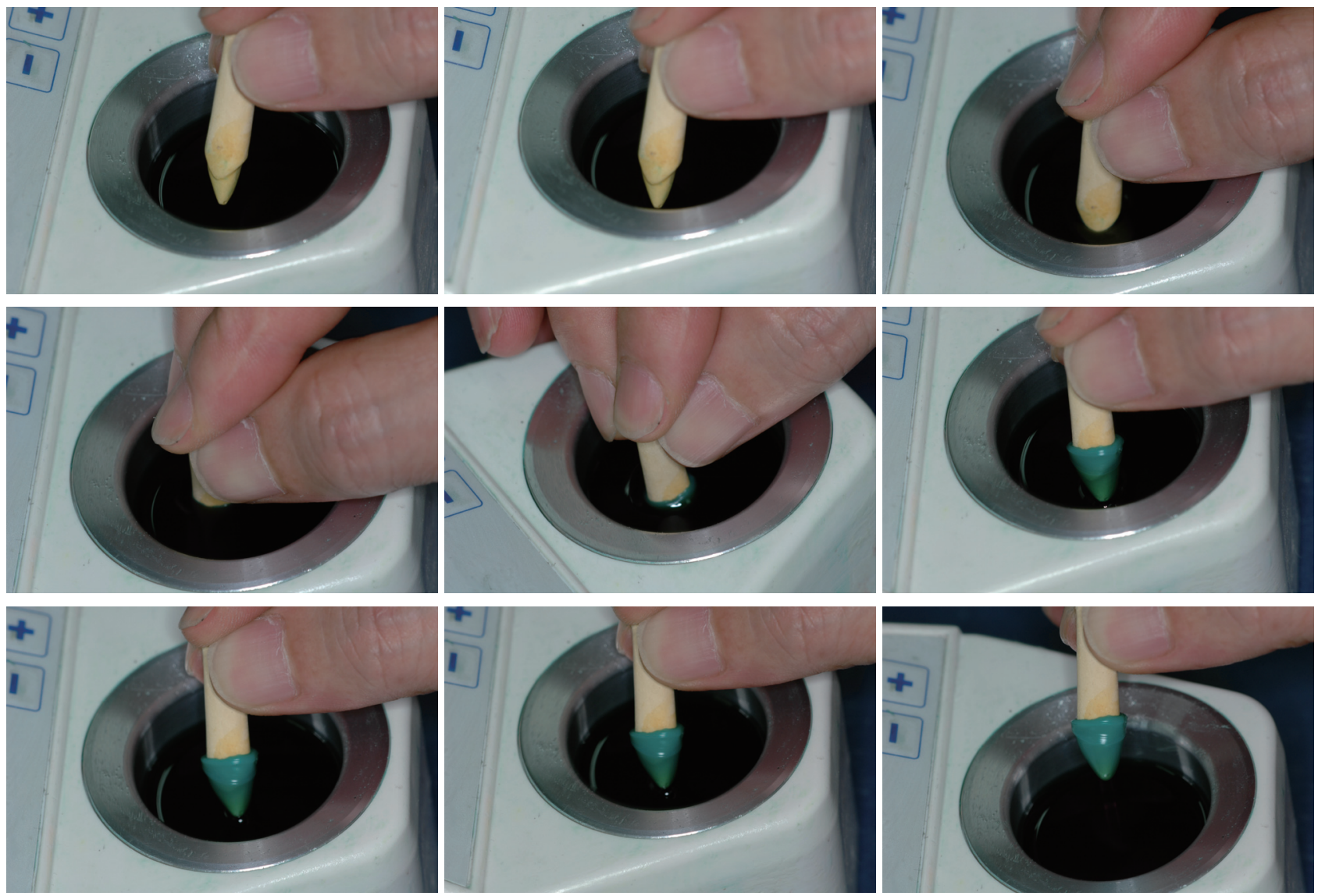

Fig 2. Sequence of dipping method.
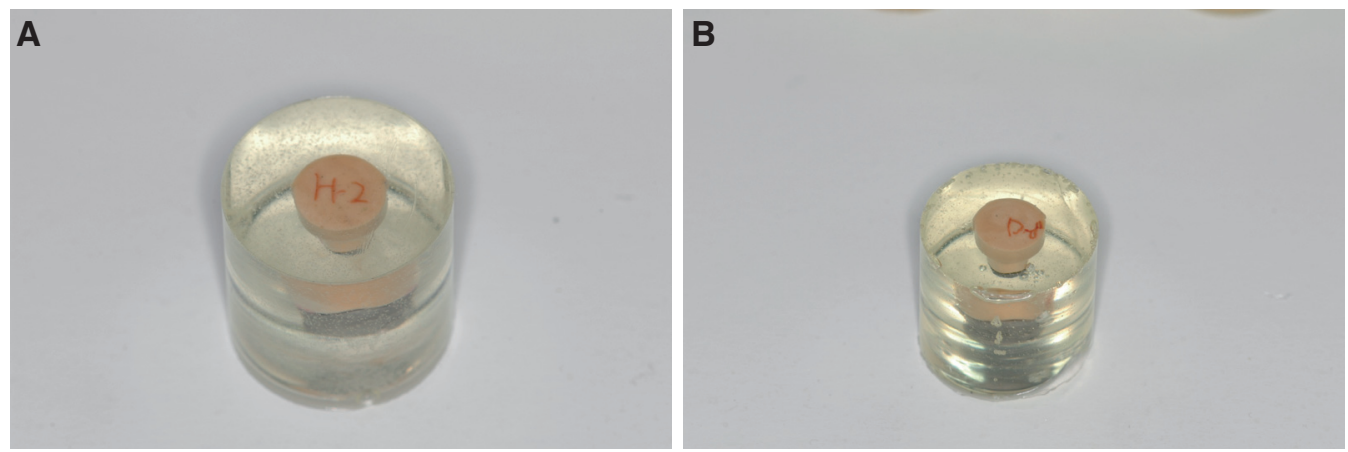

Fig. 3. Epoxy mount of addition method (A) and dipping method (B).

\section{3. 시편의 절단과 연마}

에폭시 마운트에 의해 매몰된 시편들은 경화 후에 마 운팅 컵에서 제거되었으며 절단기(TechCut 5, Allied)를 사용하여 순측 치경연 가장 깊은 곳과 설측 치경연 가장
깊은 곳(치축방향)을 연결한 순설 방향으로 절단되었다. 이 때 절단 날의 회전 수(RPM)는 2700 , 시편의 이동 속 도는 $2.0 \mathrm{inch} / \mathrm{min}$ 로 조절되었다. 절단면들의 연마는 사 포(grit 320, 600, 1500)가 부착된 그라인더(MetPrep 3, Allied)를 사용하여 시행하였다(Fig. 4, 5). 

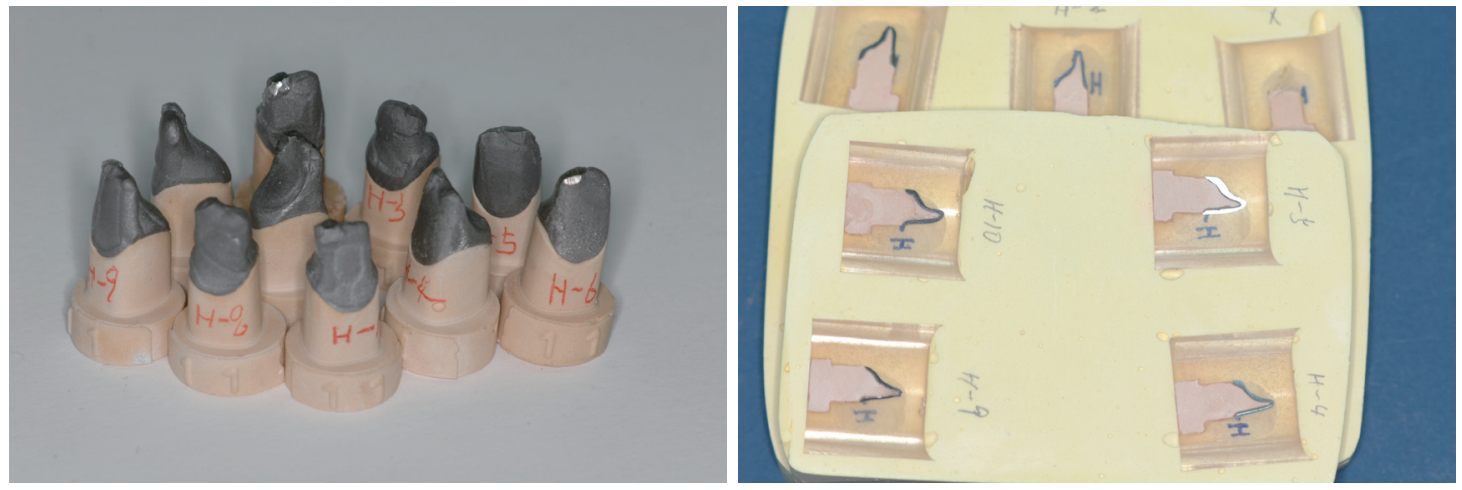

Fig. 4. Addition method specimen.
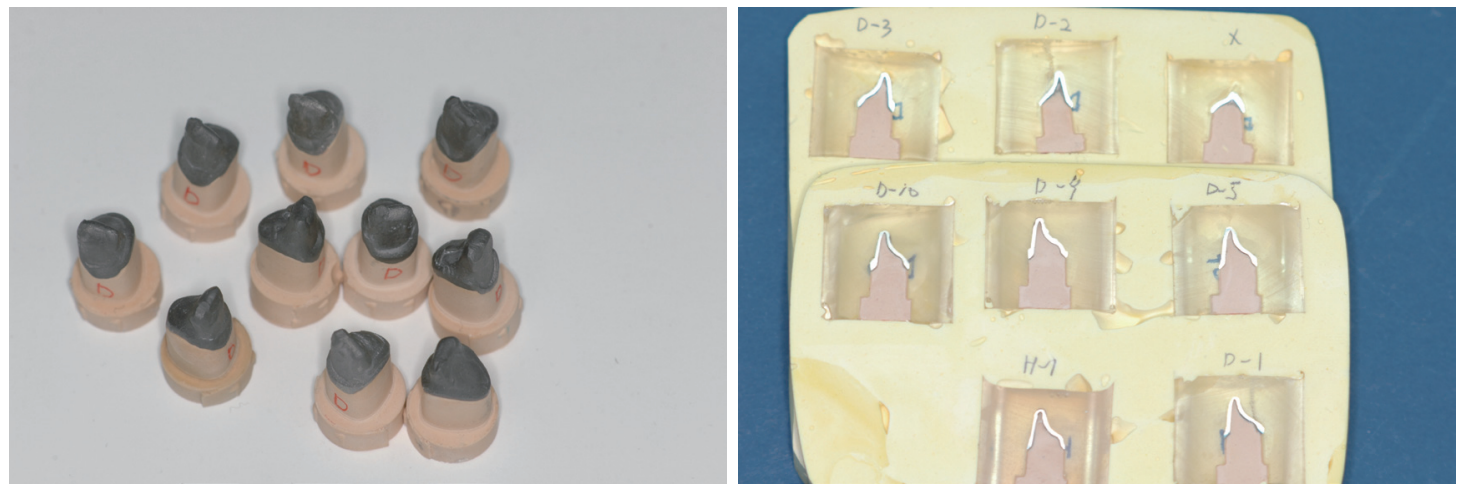

Fig. 5. Dipping method specimen.

\section{4. 내면 간격의 측정}

각 시편들의 내면 간격은 배율이 x140으로 조절된 디 지털 현미경(KH-7700; Hirox, Tokyo, Japan)을 이용하 여 7 개 지점을 측정하였으나 연마 시 모형이 파절이 발 생할 가능성이 있는 변연과 절단연을 제외한 4개 지점 을 측정 하였다(Fig. 6).

\section{5. 통계 처리}

통계처리는 SPSS 20 프로그램을 이용하여 분석하였 다. 반복첨가법과 침적법을 이용해서 제작된 코핑의 내 면 불일치 평균값 비교는 t-test로 유의성을 검증하였다. 통계적 유의수준은 0.05 로 하였다.

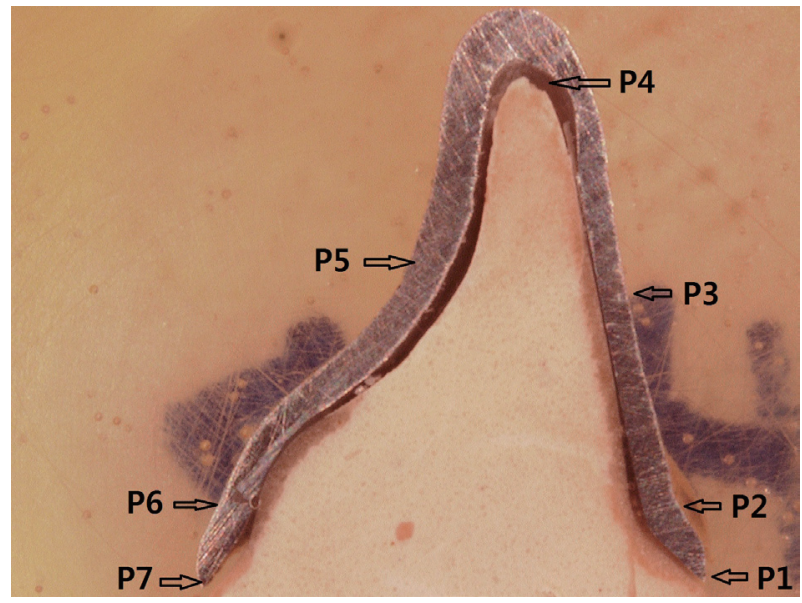

Fig. 6. Measurement of margin and internal gap using digital microscope at $\mathrm{x} 140$ magnification \& Schematic representation of measuring point.

P1: Marginal Area, P2: Chamfer, P3: Labial Surface, P4: Incisal Area, P5: Lingual Fossa, P6: Lingual Chamfer, P7: Marginal Area. 


\section{결과}

반복첨가법과 침적법의 차이를 알아보기 위해 제작된 지대치의 내면 접합도를 측정하였다.

측정된 결과 $\mathrm{P} 2,3,5,6$ 지점의 평균(표준편차)는 Table 2과 같이 나타났다.

측정된 값들에 대한 동질성 검정을 shapiro-wilk test 수행한 결과 두 방법에서 $P>0.05$ 로 정규성을 띠는 것 으로 확인하였으나, $\mathrm{P} 3$ 지점에서 $P<0.05$ 으로 나타나 유의한 차이를 나타내었다. 이 결과를 토대로 t-test를 이 용하여 제작된 지대치와 substructure의 적합도 측정값 평균을 비교한 결과는 전반적으로 유의한 차이를 보이 지 않았으나 $(P>0.05), \mathrm{P} 3$ 지점만이 유의한 것으로 나타 나고 있다.

적합도 비교는 margin wax로 처리하지 않은 $\mathrm{P} 1, \mathrm{P} 7$ 과 $\mathrm{P} 4$ 지점은 주조 수축과 그라인딩 시 파절 양상이 보여 실 험에서 제외하였다.

반복첨가법과 침적법의 적합도의 유의한 차이는 제작 된 시편을 분석한 결과 $\mathrm{P} 3$ 지점만 제외하고 유의한 차이 가 없는 것으로 확인 되었다 $(P>0.05)$.

\section{고찰}

치과치료의 기술이 발달함에 따라 재료나 제작기계의 발달은 급속하게 진행되고 있다.

보철 제작 부분에서 기공방식의 변화도 빠르게 변화 되고 있으며, 치료의 성공여부에 결정적으로 기여하고 있다.

납형제작은 기공과정 중 주조체가 제작되기 전 단계 로 중요도는 그 결과물의 성공에 결정적 요인으로 작용 하고 있다.
통상적으로 사용되는 반복첨가법은 오랜 숙련과 긴 작업시간이 필요하고 일률적 두께의 제작이 어려운 점 과 적합도가 좋지 않은 문제점이 있어 임상절차에 따라 반복첨가법과 침적법에 의한 금속 도재 하부구조물을 각각 10 개씩 제작하였고, 제작된 금속 도재 하부구조물 의 적합도를 평가할 때 주요부위의 지정은 선행연구 ${ }^{3,4}$ 에서 발표된 연구방법을 참고하여 본 연구에 맞게 수정 하여 사용하여 반복첨가법과 침적법의 차이점을 비교, 분석, 평가하여 침적법의 활용 방안을 제시하는데 의의 가 있다.

실험방법으로는 시편들을 에폭시 마운트에 매몰하여 절단기로 순측 치경연 가장 깊은 곳과 설측 치경연 가장 깊은 곳(치축방향)을 연결한 순,설방향으로 절단하여 측 정하였고, 측정지점은 $\mathrm{P} 2, \mathrm{P} 3, \mathrm{P} 5$ 와 $\mathrm{P} 6$ 총4지점으로 나 눠 금속 도재 하부구조물에 미치는 영향을 각 부위별로 측정한 결과 값으로 통계 분석하였다.

본 실험의 결과는 Table 2 와 같이 두 방법에서 유의한 차이가 나타나고 $(P<0.05), P 3$ 지점을 제외한 부위는 유 의한 차이가 발견되지 않았다 $(P>0.05)$.

고무적으로 $\mathrm{P} 3$ 지점의 우수한 적합도는 이중관 같은 정밀보철제작과 구치부 내면의 적합도 증가에 도움이 될 것이라 사료된다.

치과에서 사용되는 고정성 보철물의 적합도 측정에 있어서 기준이나 그 값에 대한 규정이 있는 것은 아니지 만 McLean 과 Fraunhofer ${ }^{6}$ 은 P3, P4부위를 통상적으로 $120 \mu \mathrm{m}$ 을 넘지 않는 것으로 제시하고 있으며, 2011년에 $\mathrm{Reich}^{3}$ 의 연구에서 구강 내 금속 도재 하부구조물을 시 적하여 측정한 부위별 cement thickness의 평균을 100 $284 \mu \mathrm{m}$ 정도로 보고하였다. 침적법으로 제작된 측정값도 $120 \mu \mathrm{m}$ 을 넘는 값은 거의 없는 것으로 나타나고 있다.

침적법은 가철 된 지대치를 wax porter에 dipping wax

Table 2. Mean (SD) of internal fit for substructure according to different addition method and dipping method at each four measuring point (unit: $\mu \mathrm{m}$ )

\begin{tabular}{|c|c|c|c|c|c|}
\hline \multirow{2}{*}{ Measurement location } & \multicolumn{2}{|c|}{ Addition method } & \multicolumn{2}{|c|}{ Dipping method } & \multirow{2}{*}{$P$ value } \\
\hline & Mean & SD & Mean & $\mathrm{SD}$ & \\
\hline P2 & 97.7 & 37.0 & 91.3 & 27.5 & 0.666 \\
\hline P3 & 97.2 & 45.3 & 41.6 & 14.0 & 0.004 \\
\hline P5 & 159.2 & 82.9 & 111.9 & 36.3 & 0.115 \\
\hline P6 & 119.0 & 33.3 & 108.7 & 78.3 & 0.706 \\
\hline
\end{tabular}


를 녹여 넣었다 빼내는 방법으로 균일한 응력이 지대치 표면에 작용하여 주름이나 결손이 없는 완벽한 내면은 적합 시 시간 절약과 균일한 두께 조절이 가능하여 일률 적인 금속 두께를 형성 할 수 있다.

경험과 반복 실험으로 얻은 wax 용융온도는 금속 도 재 하부구조물 제작할 때 차이는 있지만 $88-91^{\circ} \mathrm{C}$ 일 때 대략 $0.35-0.5 \mathrm{~mm}$ 균일한 두께를 얻을 수 있었다.

방법은 Fig. 2와 같이 기포를 밀어내는 방법으로 지대 치 측면모서리 부위를 먼저 넣고 C자형을 그리며 전체 를 집어넣어다 역순으로 들어 올려 wax의 수축성 기포 의 방지와 균일한 wax두께를 얻기 위해 지대치 모서리 의 꼭지점이 reservoir 역할을 하게 dipping porter에 잠 시 머물렀다 올리면 침적법의 가장 큰 문제점으로 제시 된 지대치와 납형 사이에 발생할 수 있는 공간은 보이지 않았고, 반복첨가법에서 얻지 못한 단점들도 해결할 수 있었다.

본 실험에서 본 연구는 wax라는 물성 때문에 반복첨 가법과 침적법으로 제작 된 상태를 실험할 수 없었고, 주조 후 적합도는 오차 범위와 변수 요인으로 작용될 수 있었다. 또한 비교할 실험의 선행연구가 행해지지 않아 어려웠다.

그러나 침적법은 작업시간의 단축, 지대치의 균일한 응력의 발생으로 분리가 쉽고, smooth한 주조단면 및 dipping wax의 elastic한 특성으로 깨끗한 주조체 내면을 얻을 수 있는 점 등으로 금속 도재 하부구조물 제작의 활용 방안으로써 타당하다고 사료된다.

\section{결론}

본 연구에서는 금속 도재 하부구조물 제작 시 반복첨 가법과 침적법의 차이가 지대치 내면 적합도에 미치는 영향을 측정하기 위하여 디지털 현미경으로 관찰한 결 과 다음과 같은 결론을 얻었다.

1. Chamfer (P2), Lingual surface (P5), Lingual chamfer (P6) 부위에서의 반복첨가법과 침적법의 유의차이는 나타나지 않았다 $(P>0.05)$.

2. Labial surface $(\mathrm{P} 3)$ 부위에서는 반복첨가법과 침적 법에서 유의차이를 보였다 $(P<0.05)$.

3. 이상의 실험 결과로 침적법을 임상에 사용해도 무 방하다고 생각된다.

\section{References}

1. Kim KB, Kim WC, Kim HY, Kim JH. An evalualuation of marginal fit of three-unit fixed dental prostheses fabricated by direct metal laser sintering system. Dent Mater 2013;29:e91-6.

2. Kwuan EJ, Kim SH, Kim JJ, Kim JS, KIM TS, Park NG, Park JH, Park HB, Sung HG, Lym SD, Lee BG, Lee IG, Lee JH, Jung IS, Choei YS, Choei JE, Hwang KS, Hwang SS. Fixed crown and bridge of engineering education research. $4^{\text {th }}$ ed. Seoul; Daihak Publishing Company; 2008. p. 210-2.

3. Reich S, Uhlen S, Gozdowski S, Lohbauer U. Measurement of cement thickness under lithium disilicate crowns using an impression material technique. Clin Oral Investig 2011;15:521-6.

4. Colpani JT, Borba M, Della Bona A. Evaluation of marbinal and internal fit of ceramic crown copings. Dent Mater 2013;29:174-80.

5. McLean JM, von Fraunhofer JA. The estimation of cement film thickness by an in vivo technique. $\mathrm{Br}$ Dent J 1971;131:107-11.

6. Fransson B, Olio G, Gjeitanger R. The fit of metal ceramic crowns, a clinical study. Dent Mater 1985;1: 197-9. 


\section{금속 도재 하부구조물 제작 시 침적법의 타당도 실험}

\section{이완선 ${ }^{1}$, 임수현 ${ }^{2}$, 김욱태 ${ }^{3 *}$}

${ }^{1}$ 고려대학교 보건과학 대학원, ${ }^{2}$ 연세대학교 치과생체재료공학교실, ${ }^{3}$ 신한대학교 치기공학과

목적: 본 연구는 상악 중절치(\#11) 금속 도재 하부구조물(metal-ceramic substructure) 제작 시 반복첨가법(addition method)과 침적법(dipping method)의 차이점을 비교 분석하여 작업의 효율성의 차이를 평가하여 침적법의 활용 방안 을 제시하는 것이 주요 목적이다.

연구 재료 및 방법: 주 모형과 경석고 복제모형을 제작하여 반복첨가법과 침적법으로 코핑을 각 10 개씩 20 개를 제작하 여 실험하였다. 코핑은 경석고 지대치 모형에 고정시키고 에폭시 마운팅 컵(epoxy mounting cup)에 매몰하였다. 시편 은 경화 후 절단기를 사용하여 순,설방향으로 절단하여 사포 후 디지털 현미경을 이용하여 4지점을 측정하였다.

결과: t-test를 이용하여 제작된 지대치 substructure의 측정값 평균을 비교한 결과는 전반적으로 유의한 차이가 나타나 고 있다 $(P<0.05)$.

결론: 본 연구의 결과는 금속 도재 하부구조물 제작 시 반복첨가법과 침적법의 유의적 차이가 없으므로 활용 방안으로 써 제시 될 수 있다.

(구강회복응용과학지 2015;31 (1):26-32)

주요어: 침적법; 금속도재 하부구조물; 타당도; 반복첨가법 